\title{
Overview of Oral Cancer
}

\author{
Kalu U. E. Ogbureke ${ }^{1, *}$ and Christopher Bingham ${ }^{2}$ \\ ${ }^{1}$ Department of Oral Biology, College of Dental Medicine, \\ Georgia Health Sciences University, Augusta, Georgia, \\ ${ }^{2}$ Department of Periodontology, College of Dental Medicine, \\ Georgia Health Sciences University, Augusta, Georgia, \\ USA
}

\section{Introduction}

Cancer is the second most common cause of death in the Western world, after cardiovascular diseases (Johnson, 1991; 2001). Worldwide, an estimated cancer incidence of about 10 million was reported for the year 2009 (Jemal et al., 2010), and 1 out of every 3 persons is estimated to suffer from cancer by the age of 75 years (Johnson, 1991; 2001). It is also estimated that about 7.9 million people world-wide will die from cancer this year (Jemal et al., 2010), accounting for nearly $12 \%$ of deaths worldwide (Jemal et al., 2010). In the United States alone, an estimated 569,490 deaths from cancer are projected for the 2010 (Jemal et al., 2010). Recent published estimates of worldwide frequency of the 16 major cancers indicate that in developing countries with a high prevalence of infectious and nutritional diseases, cancer remains a major cause of death (Parkin, Laara and Muir, 1988). This may account partly for the current statistics whereby more than half the global incidence of cancer is from the so-called developing countries, since an estimated $70-80 \%$ of the global population resides in these areas (Parkin et al., 1998). The estimated annual incidence of cancer ranges from 48 to 225 per 100,000 in developing countries (Parkin et al., 1998).

\section{Oral cancer - Epidemiologic overview}

"Oral cancer" encompasses all malignancies originating in the oral cavity. Oral cancer ranks sixth in the overall incidence for the 10 most common cancer sites worldwide and third in the developing countries (Johnson, 2001)). There is also a marked disparity in geographic incidence between the "high" and "low" prevalence areas of the world, suggesting major geographic differences in risk factors (Johnson, 1991; 2001). Most of these factors have been identified through epidemiologic studies.

For statistical purposes, oral cancer is often grouped together with cancers of the pharynx as "oropharyngeal" cancer (Daftary et al., 1992). In the Western world, oral cancer is relatively uncommon, and in the context of all malignant tumors, incidence in the United States and Great Britain ranges from 2 to 3\% (Batsakis, 1979; Jemal et al., 2008). Relative incidence of

* Corresponding Author 
up to $5 \%$ however has been reported for the United States (Batsakis, 1979), and higher rates have been reported for the so-called "high risk" areas of Europe with incidence equally varying with different socioeconomic groups within these areas (Johnson, 1991). Worldwide, it is estimated that about 300,000 people will be diagnosed with oral cancer in 2010 (Jemal et al., 2010). Of these, 126,000 will die from the disease (Jemal et al., 2010). In the United States alone, an estimated 35,000 new cases of oral cancer will be diagnosed in 2009 with an estimated 7,500 resultant deaths (Jemal et al. 2008). In the Asian subcontinent of Bangladesh, India, Pakistan, and Sri Lanka, oral cancer is the most common malignancy, accounting for about one-third of all malignancies within the subcontinent (Daftary et al., 1991; Jonson, 2001). About 100,000 new cases are estimated to occur annually in these regions that include Burma, Cambodia, Malaysia, Nepal, Singapore, Thailand, and Vietnam (Daftary et al., 1991).

The paradox in the foregoing gloomy statistics is that, although the oral cavity and oropharynx are easily accessible to dentist and physicians for routine examinations and the biopsy of suspicious lesions that often present with outstanding features, early diagnosis has been painfully slow when compared with the enhanced early detection of breast, colon, prostate cancers, and melanoma (Mashberg A, 2000). As a result, the mortality rate from oral cancer for the past three and a half decades has remained high (over 50\%) in spite of new treatment modalities. In contrast, there has been a considerable decrease in mortality rates for cancers of the breast, colon, prostate, and melanoma during the same period (Mashberg A, 2000). Examination of the colonic mucosa, which requires endoscopic examination for evaluation of colon cancer, reveals $36 \%$ of localized colon cancers among the United States population (Mashberg A, 2000). An identical percentage of localized oral/oropharyngeal cancers are diagnosed without endoscopy among the same population (Mashberg A, 2000). This paradox was eloquently summed up in a four decades-old publication highlighting ". . . the poor prognosis of a form of cancer, which presents exceptionally good opportunity for early treatment" (Banoczy and Csiba, 1976; Wright 1994).

The impediment to early diagnosis of oral and oropharyngeal cancers, despite increased assiduousness on the part of dentists and oral physicians in their examination of patients at risk, stems from the persistence of archaic paradigms, and the lack of an easily available diagnostic adjunct. In order to increase the early detection of oral cancers, and by so doing increase the survival rates of oral cancer patients, there is therefore the need to identify diagnostic screening modalities that identify early oral malignant lesions with precision.

About $95 \%$ of oral cancers are classified histologically as oral squamous cell carcinoma (OSCC; Mashberg, 2000; Johnson, 2001, Sargeran et al., 2008). The remaining 5\% include such histologic variants as oral verrucous carcinoma, adenosquamous carcinoma, adenoid squamous cell carcinoma, mucoepidermoid carcinoma, and basaloid squamous cell carcinoma. Mucoepidermoid carcinomas are malignancies of salivary gland origin and, within the oral cavity, arise from minor salivary glands, while adenosquamous carcinomas are currently believed to arise from the oral mucosa with subsequent glandular changes among the tumor cells. Basaloid squamous cell carcinoma, a relatively newly recognized entity, is a rare histologic variant of OSCC with marked predilection for the base of tongue in addition to the supraglottic larynx and hypopharynx. Often included in the remainders are metastatic carcinomas from regional sites distant to the oral cavity. 


\section{Etiologic risk factors for oral cancer}

Oral cancer is a multifactorial disease. Exposure to one of three broad groups of carcinogenic stimuli, namely, chemical, physical, and viral, is known to induce cancer in genetically and systemically conditioned oral mucosa. Within the oral cavity, it appears that carcinomas are caused predominantly by chemical carcinogens, although evidence implicating viral and physical stimuli in the development of some oral cancers continues to mount (Syrjanen, 2005; Reddout et al., 2007). The pathogenesis of oral cancer is equally complex, and exposure to carcinogens does not inevitably result in the development of oral cancer. This is because a number of familial, dietary, hormonal, and sex-related factors are known to modulate neoplastic processes generally. Tobacco and alcohol have emerged as the most important culprits contributing to the etiology of oral cancers. Other factors frequently cited are ultraviolet light, nutritional and dietary factors, precancerous lesions, immunosuppression, genetic, and dental factors.

\subsection{Tobacco and tobacco products}

An association between the use of tobacco and oral cancer can be traced to the early $18^{\text {th }}$ century, when lip cancer was observed with some frequency in tobacco users (Sawyer and Wood, 1992). The strong association of cancers of the oral cavity and oropharynx with tobacco use is well established (Johnson, 2001). Epidemiological studies show that the risk of developing oral cancer is five to nine times greater for smokers than for nonsmokers, and this risk may increase to as much as 17 times for heavy smokers of 80 or more cigarettes per day (Neville and Day, 2002). Approximately 80 percent of oral cancer patients are smokers, and this is two to three times greater than that of the general population (Silverman and Griffith, 1972; Blot et al., 1988; Mashberg et al., 1993; Jovanovic et al., 1993; Andre et al., 1995, Lewin et al., 1998). In addition, treated oral cancer patients who continue to smoke have a two- to six- times greater risk of developing a second malignancy of the upper aerodigestive tract than those who stop smoking (Silverman and Griffith, 1972; Silverman and Shillitoes, 1998).

Oral smokeless tobacco (snuff and chewing tobacco) have also been associated with an increased risk for oral cancer (Brown et al., 1965). In one study of women in the southern United States, chronic users of snuff were estimated to have a four times greater risk of developing oral cancer (Winn et al., 1981, Johnson, 2001). In addition, a significant number of oral cancers in smokeless tobacco users develop at the site of tobacco placement. However, the use of smokeless tobacco appears to be associated with a much lower cancer risk than that associated with smoked tobacco. For example, although the state of West Virginia has the highest consumption of chewing tobacco in the United States, the incidence of oral cancer in West Virginia is below the U.S. national average (Bouquot and Meckestroth, 1998). Recent studies from Scandinavia have suggested that the use of Swedish snuff (which is nonfermented and has lower nitrosamine levels) is not associated with an increased risk for oral cancer (Johnson, 2001; Neville, 2002).

The habit of oral smokeless tobacco use is evolving as "fashionable" amongst the youth in many Western countries, and may partly account for spikes in the rate of oral cancers and potentially malignant lesions observed in this age group in recent decades (Johnson, 1991). The importance of teenage use of smokeless tobacco lies in the considerable length of time 
that the oral mucosa of teenagers indulging in this habit are bathed in high concentrations of numerous carcinogens contained in smokeless tobacco (Sawyer and Wood, 1992). In addition to carcinogens usually associated with smoking, smokeless tobacco contains ${ }^{210}$ polonium (originating from phosphate fertilizers used to grow tobacco), 226radium, and 210lead (Main and Lacavalier, 1988). Furthermore, tobacco-specific nitrosamines present in smokeless tobacco, and readily extracted in saliva and further enhanced in alkaline environments, often are of higher concentrations than in cigarette smoke (Sawyer and Wood, 1992).

In India and Southeast Asia, the chronic use of betel quid (paan) in the mouth has been strongly associated with an increased risk for oral cancer (Murti et al., 1985; Murti et al., 1995). The quid typically consists of a betel leaf that is wrapped around a mixture of areca nut and slaked lime, usually with tobacco and sometimes with sweeteners and condiments. The slaked lime results in the release of an alkaloid from the areca nut, which produces a feeling of euphoria and well-being in the user. Betel quid chewing often results in a progressive, scarring precancerous condition of the mouth known as oral submucous fibrosis. In India, one study showed a malignant transformation rate of 7.6 percent for oral submucous fibrosis (Murti et al., 1985).

Marijuana use is also considered to be a potential risk factor and may be partly responsible for the rise in oral cancers seen among young adults (Zhang et al., 1999; Silverman, 2001; Schantz and $\mathrm{Yu}, 2002)$. Marijuana smoke contains known carcinogens such as benzopyrene and benzanthracene (aromatic hydrocarbons), and the concentration of these carcinogens is postulated to be considerably higher than that in cigarette smoke (Sawyer and wood, 1992). However, further epidemiological studies are necessary to confirm the purported association of marijuana and oral cancer, particularly in younger patients.

\subsection{Alcohol}

The relationship between alcohol, particularly hard liquor, and squamous cell carcinoma has been recognized for a long time (Wynder, 1971), and has been identified as a major risk factor for cancers of the upper aerodigestive tract (Neville and Day, 2002). What presented as a significant challenge, until recently, was the assessment of the independent role of alcohol in oral cancers due to the difficulty in separating the effects of heavy alcohol consumption from those of smoking and other risk factors, including nutritional (Kato and Nomura, 1994). Most heavy consumers of alcohol beverages also are heavy smokers.

In studies controlled for smoking, moderate-to-heavy drinkers have been shown to have a three- to nine- times greater risk of developing oral cancer (Blot et al., 1988; Mashberg et al., 1993; Jovanovic et al., 1993; Andre et al., 1995; Lewin et al., 1998). One study from France showed that heavy drinkers, consuming more than 100 grams of alcohol per day (a typical serving of beer, wine, or liquor approximates 10 to 15 grams of alcohol), had a 30 times greater risk of developing oral and oropharyngeal cancer (Andre et al., 1995). Thus, it would appear that smoking is not a necessary prerequisite for alcohol induced cancers. Of greater significance however is the synergistic effect of alcohol and smoking; some subsets of patients who are both heavy smokers and heavy drinkers can have over one hundred times greater risk for developing a malignancy (Blot et al., 1988; Andre et al., 1995). 
While the mechanism of alcohol-induced carcinogenesis remains unclear, it is apparent that alcohol acts primarily as a co-carcinogen or promoter. Carcinogenesis also may be related to nutritional deficiencies associated with alcoholism. Systemically, alcohol may lead to impaired absorption of nutrients and vitamins. It has been suggested that alcohol acts as a solvent facilitating the entry of carcinogens into exposed cells (Sawyer and Wood, 1992). In addition to creating a nutritional deficiency state (Harris et al., 1997; Johnson, 2001), alcohol may alter epithelial cell metabolism, or suppress immunity (Cotran, Kumar and Robbins, 1989). There is some evidence that carcinogenic contaminants rather than ethanol may be responsible for the increased incidence of alcohol-associated cancers (Bennie, 1976).

\subsection{Human Papilloma Viruses (HPV)}

The role of HPV as an etiologic agent in cancer was first recognized in the uterine cervix (where it is present in about $99.7 \%$ of cases), and the prognostic significance of HPVassociated cervical cancer is now well established (Clifford, Boyle and Franceschi S, 2003; Reddout, 2007). HPV-16 and -18 are the major high-risk types and predominate in invasive anogenital cancers (Clifford et al., 2003; Reddout, 2007). On the other hand there is as yet no clear evidence to support a causative role for HPV in OSCCs, and any potential pathogenic mechanism of HPV-associated OSCCs is still confounding. At best, an association between $\mathrm{HPV}$ infection and oral cancer is accepted by most investigators in this field.

In oral lesions, HPV-16 is by far the most common subtype associated with OSCCs and oral premalignant lesions (OPL) exhibiting epithelial dysplasias (Reddout, 2007). HPV-16 DNA has been identified in primary tumors of the tonsil, hypopharynx, oral cavity, tongue, and nasopharynx, as well as in cell-lines derived from these regions (Syrjanen, 2005; Reddout, 2007). Metastatic lymph nodes lesions have also been shown to contain DNA of the same HPV type as in the primary tumor in $76 \%$ of the cases, supporting the involvement of HPV in the development of OSCC (Clifford et al., 2003; Syrjanen, 2005; Reddout, 2007).

The prevalence of HPV-16 in OSCC is now considered to be as high as 50\% if not more, making it likely that every alternate OSCC patient is HPV-16 positive (Syrjanen, 2005; Reddout, 2007). The association is strongest in the oropharynx, most notably in the tonsil and base of tongue, which present more frequent basaloid histomorphology and less frequent p53 mutations (Clifford et al., 2003). In addition, HPV-16 has been detected in extremely low copy numbers (compared to copy numbers in OSCC and dysplastic OPLs) in some human "normal" oral mucosa (NOM), suggesting that a threshold viral DNA copy number is required for the role of oncogenic HPVs in oral carcinogenesis. HPV-18 is far less commonly associated with oral cancers, and has been found in up to just 14 percent of cases (Kang and Park, 2001).

It is now established that the products of two early genomic regions of high-risk HPVs, E6 and E7, are capable of forming specific complexes with vital cell cycle regulators (Kang and Park, 2001). For example, E6 binds to p53 to induce p53 degradation, while E7 interacts with $\mathrm{pRb}$ resulting in blockage of the downstream activities of $\mathrm{pRb}$ (Kang and Park, 2001). Both p53 and pRb are oncosuppressors, and the overall outcome of their functional dysregulation is an uncontrolled DNA replication and impairment of apoptosis. The combined effects of apoptotic impairment and uncontrolled DNA replication are increased tendency towards cellular transformation and tumorigenesis. 


\subsection{Nutritional factors}

The role of metabolic and dietary deficiencies in the etiology of OSCC was long suspected before concrete evidence began to emerge. Peterson (1919) and Kelly (1919) independently described the symptom complex of chronic dysphagia, mucosal atrophy of the hypopharynx, and chronic anemia in middle-aged women who also had cricoid carcinomas. The term sideropenic dysphagia was introduced, and used to describe the disease complex now referred to as Paterson-Kelly (or Plummer-Vinson; P-V) syndrome. P-K syndrome is marked by diminished iron stores and the absence of stainable bone marrow iron. Other components of the syndrome include riboflavin and other vitamin deficiencies. Subsequent studies by Ahlbom (1936) confirmed not only the importance of P-K syndrome in the development of pharyngeal cancers, but also showed that this applied to the buccal mucosa, tongue, and all levels of the esophagus.

There is a high incidence of oral cancer in parts of the world where iron deficiency is endemic (Prime, MacDonald and Rennie, 1982). Iron metabolism is essential for the overall integrity and health of epithelia of the digestive tract, and its importance may lie in its contribution to normal enzymes. Rennie and MacDonald (1982), and Rennie, MacDonald and Dagg (1982) demonstrated quantitative histologic changes in the oral epithelium in human iron deficiency anemia and in experimental iron deficiency in hamsters. The authors noted that the oral epithelium in iron deficiency is atrophic with reduced maturation compartment, but an increased keratinized compartment (Rennie et al., 1982). Subsequent cell kinetic studies by Rennie and MacDonald (1984) showed increased cell proliferation, indicating that, in spite of the atrophy, epithelial turnover is rapid. This observation suggested a possible increase in susceptibility to chemical carcinogens due to both an increase in the population of potentially vulnerable dividing cells and to a more permeable epithelium.

Increased cancer risks also are attributable to dietary factors, notably low intake of fruits and vegetables (Winn et al., 1984; Winn, 1995). Increased consumption of fruits and vegetables were said to be protective against oral cancer when controlled for demographic characteristics, tobacco and alcohol use, relative weight, and the intake of other food items (Winn et al., 1984). The reduction of risk is seen to be consistent with the hypothesis that Vitamin C and/or Vitamin A and B-carotene intake is associated with a reduced risk of oral and pharyngeal cancers (Ibrahim, Jafarey and Zuberi, 1977). Interestingly, intervention trial studies with B-carotene and Vitamin A in patients with oral precancer have been shown to result in substantial regression of the lesions (Stich et al., 1988a, 1988b).

Degenerative changes occur in riboflavin deficiency, a frequent finding in alcoholics. This may partly explain the relationship between alcoholism and oral cancer (Wynder and Klien, 1965). It also may be that alcohol increases the risk of oral cancer by lowering nutritional status via a substitution of non-nutritive calories for vitamins, minerals, and other elements; alternatively, that poor nutrition allows the deleterious effects of alcohol to be manifested.

\subsection{Impaired immunity}

Generally, patients with malignancies have some degree of immunosuppression that tends to worsen with the progression of their malignancy. Immunosuppression appears to predispose some individuals to an increased risk for oral cancer. Carcinomas of the lip have been reported in a number of kidney transplant patients receiving immunosuppressive 
medications, and oral carcinomas have been documented in young AIDS patients (van Zuuren, de Visscher JGAM, Bouwes Bavinck JN, 1988; Flaitz et. al., 1995; de Visscher, Bouwes Bavinck JN and van der Waal, 1997; Flaitz and Silverman, 1998). It is however still debated as to whether immunosuppression in malignant disease represents an effect or a cause of the malignancy. Some studies have suggested that immunosuppressive states may represent the effect rather than the cause of cancer (Johnson, 1991), while others have suggested that OSCC, despite its local manifestations, is most likely a "regional" disease process that becomes "clinically significant" only when the patient's immunologic status is altered (Mashberg and Samit, 1989).

It would appear however that a factor such as advanced age, which diminishes immune competence and immune cellular surveillance, increases the risks of oral cancer. Overt immune suppression induced by chemicals or drugs, or caused by specific viral infections such as the human immunodeficiency virus (HIV), or Epstein Barr virus (EBV), increases the risk of oral cancers. Barr et al. (1989); Bradford et al. (1990) variously suggested that HPV may play an etiologic role in squamous cell carcinoma in renal allograft recipients.

\subsection{Oral Premalignant Lesions}

Oral premalignant lesions (OPLs) are lesions, often presenting on the oral mucosa, which possess a higher than normal propensity for transformation to OSCC with time if untreated. The current model for oral carcinogenesis postulates a step-wise transformation from normal to pre-malignant to invasive carcinoma phenotype. Histologically, the transition process involves progression from benign epithelial hyperplasia to various degrees of epithelial dysplasia (mild, moderate, severe) to carcinoma in situ, and finally to invasive OSCC. With respect to transition to OSCC, oral leukoplakia, oral erythroplakia, and speckled leukoplakia are the most notable and most studied OPLs (Figure 1.1). The transition rate of oral leukoplakia to OSCC is estimated at between 4 and $18 \%$, while that of OLP is to be between 1 and $4 \%$.

Although erythroplakia is not nearly as common as leukoplakia, it is much more likely to show dysplasia or carcinoma histologically. In a study by Shafer and Waldron (1975) of biopsies of erythroplakic lesions from 65 patients, all cases showed some degree of epithelial dysplasia: 51 percent showed invasive squamous cell carcinoma; 40 percent were carcinoma in situ or severe epithelial dysplasia; and the remaining 9 percent demonstrated mild-tomoderate dysplasia (Shafer and Waldron, 1975). Thus, true clinical erythroplakia is a much more worrisome lesion than leukoplakia (Mashberg and Samit, 1995). Likewise, in a mixed leukoplakia-erythroplakia (erythroleukoplakia), the erythroplakic (red component) is more likely to demonstrate dysplastic changes than is the white component, making it imperative that that biopsy sites be selected to ensure that the specimen incorporates the red component. In addition, a number of studies have suggested that oral lichen planus (OLP), especially the erosive form, may be associated with an increased cancer risk, although other investigators have questioned the strength of this association (Silverman et al., 1991; Barnard et al., 1993; Eisenberg, 2000).

\section{Site distribution in oral cancer}

Symptomatic lesions present with symptoms and signs such as intraoral pain and/or dysfunction, extraoral swelling, and cervical lymphadenopathy. These signs and symptoms 
alert the clinician to the need to evaluate the oral cavity for obvious primary lesions. Site distribution in OSCC is usually described in relation to the symptomatic lesions, which are often amenable to classification under the " $\mathrm{T}$ " category of the TNM classification of malignant tumors (Neville and Day, 2002). The TNM classification allows for the clinical staging of oral malignant tumors on the basis of the size of the primary tumor, $\mathrm{T}$, the absence or presence of corresponding regional node spread, and the absence or presence of distant site/organ metastases (Neville and Day, 2002). In OSCC, T1 lesions are $2 \mathrm{~cm}$ or less in greatest dimension; T2 lesions are more than $2 \mathrm{~cm}$ but not more than $4 \mathrm{~cm}$ in greatest dimension; T3 lesions are more than $4 \mathrm{~cm}$ in greatest dimension, and T4 lesions are those that have invaded adjacent contiguous structures such as the cortical bone, inferior alveolar nerve, deep extrinsic muscles of the tongue, maxillary sinus, or salivary glands regardless of their apparent visual dimension (Neville and Day, 2002).

Early asymptomatic lesions are relatively small (T1) and, not infrequently, elude clinical diagnosis by conventional systems (Mashberg and Meyers, 1976; Neville and Day, 2002). These early asymptomatic lesions, often presenting as erythroplastic lesions, were studied by Mashberg and Meyers (1976) who consequently provided guidance toward enhanced accurate designation of sites of origin of these early asymptomatic lesions (Mashberg and Meyers, 1976). In this respect, the authors further concluded thus: "The described locations in the literature may be points of termination or extension of the lesion rather than sites of origin, e.g., a symptomatic lesion (T2 or T3) in the floor of mouth may have extended to and invaded the alveolus; hence, based on clinical and x-ray evidence, it may have been reported as a gingival or alveolar lesion" (Mashberg and Meyers (1976).

There are geographic variations in the frequency of sites of involvement, probably related to such risk factors as occupation and lifestyle, oral habits, and certain socio-cultural practices, such as the mode of tobacco use (Paymaster, 1962; Brown et al., 1965). For example, presentation of intraoral cancers among the population of the high risk areas of Southeast Asia and the Southeast United States is slightly different. Consistent with the role of the risk factors alluded to above the most prone sites in the high risk areas of Southeast Asia are the buccal, retromloar, and commissural mucosa (Paymaster, 1962; Brown et al., 1965).

\subsection{The lip}

The World Health Organization (WHO) revision of the International Classification of Diseases (ICD) defines cancer of the lips as malignant lesions of the vermilion area of the upper and lower lips (Daftary et al., 1992). Cancers in these areas are not considered intraoral cancers (Daftary et al., 1992). Over 90\% of lip cancers involve the lower lip (Neville and Day, 2002). Lip lesions are easily detectable partly because the lip is the most visible structure of the oral cavity complex. Lip squamous cell carcinomas usually arise in actinic cheilosis, a premalignant condition, which is a "cousin" to actinic keratosis of the skin. Actinic cheilosis is characterized by atrophy of the vermilion border, clinically visible as dry, scaly changes. Ulcerated foci alternating with partial healing may appear as the lesion progresses. Not infrequently, patients mistake these recurring ulcerated lesions for "fever blisters." Subsequently, the evolving cancer slowly becomes a crusted, nontender, indurated ulcer or mass (Neville et al., 2009; Silverman, Dillon and Fischbein, 1998). 
In Romania, Hungary, Yugoslavia, and parts of Canada and the United States, the vermilion area of the lips are the commonest sites of oral cancer (Johnson, 1991; 2001), and it has been reported that about half of all cases of oral cancer in the Nordic countries occur on the lips (Ringertz, 1971). The lateral aspect of the lower lip is more frequently involved than the mid-portion (Daftary et al., 1992). Race and ethnic variations in the incidence of lip cancer occur worldwide. Among most white population, the lip constitutes the most common site for oral cancer (Spitzer et al., 1975; Johnson, 1991; 2001). Considerable agreement over the association between lip cancer and occupation exists; the disease being common amongst white males who engage in outdoor occupations, such as farming and fishing, which expose them excessive sunlight (Spitzer et al., 1975; Johnson, 1991; 2001). On the other hand, lip cancer is relatively rare in black males, and females of both white and black races (Bernia, 1948; Spitzer et al., 1975; Johnson, 1991; 2001).

In a 1984 study reported by Douglass and Gammon there was variation in the incidence of lip cancer between the male non-Maori $(1.7 / 100,000)$ and the Maori $(0.2 / 100,000)$ population of New Zealand (Douglass and Gammon, 1984). The authors similarly highlighted ethnic differences in the incidence of lip cancer in Israel where males born in Israel had a higher rate of lip cancer $(3.5 / 100,000)$ than male immigrants from Europe/ America $(2.9 / 100,000)$, or Africa/ Asia $(0.8 / 100,000)$.

\subsection{The tongue and floor of mouth}

The tongue is the most common site for intraoral carcinoma and accounts for about 40 percent of all cases in the oral cavity proper, with tumors occurring on the posterior lateral border and ventral surfaces of the tongue (Neville and Day, 2002). The incidence of floor-ofmouth squamous cell carcinoma closely approximates that of the tongue (Neville and Day, 2002). In the black population however the floor of mouth distinctly is the most common site for OSCC (Batsakis, 1979). Thus, anatomically, the lateral tongue and floor of mouth (extending to the lateral soft palate and tonsillar area) combine to form a horseshoe-shaped region of the oral mucosa, which is at greatest risk for cancer development (Neville and Day, 2002). Two major factors may explain the high-risk status of this composite region: first, carcinogens in saliva pool at the floor of the mouth with the tongue providing a lid; second, this complex is covered by a thinner, non-keratinized mucosa, thus providing limited barrier to carcinogen ingress (Jovanovic et al., 1993).

\subsection{Buccal mucosa}

The mucosal surface of the cheek extends from upper to lower vestibular sulci, where the mucosa reflects itself to cover the upper and lower alveolar ridges. The buccal mucosa also forms the commissure of the lip and covers the ramus of the mandible. A number of buccal squamous cell carcinomas originate in the commisural areas before spreading posteriorly to involve the mucosa along the occlusal plane of the teeth, or at the retromolar area (Batsakis, 1979). It has been suggested that, because commissural cancers have better prognoses than buccal mucosa cancers, the former ought to be separated from the latter for purposes of site designation (Daftary et al., 1992). However, this suggestion appears not to have gained wide acceptance. Buccal cancers usually arise on the mucosa lying against the wisdom teeth, and correspond to the common site of placement of tobacco-containing quid. The lesion then grows to obscures the site of origin (Singh and von Essen, 1966; Batsakis, 1979; Daftary et al., 
1992). Results of some studies indicate a consistent increase in the incidence of buccal cancers in relation to smokeless tobacco use (Brown et al., 1965; Winn et al., 1981). These findings underscore the importance of local etiologic factors in the site distribution of intraoral cancers.

\subsection{The gingiva and alveolar ridge}

Cancer of the gingivae and alveolar ridge are usually grouped together. Squamous cell carcinomas of the gingival and alveolar ridge generally are less common than those of the lip, tongue, and floor of mouth (McCarthy and Shklar, 1964). Similar to buccal and commissural cancers, Daftary et al., (1992) suggested that lesions of the gingivae and alveolar ridge be separated because of differences in prognosis. The incidence of carcinoma of the gingivae and alveolar ridge among the rural women of the Southeast United States is relatively high (Rosenfield and Callaway, 1963). The reported incidence of cancer of the gingival and alveolar ridge in three Indian populations ranged from $0.6 / 100,000$ to $1.4 / 100,000$ per annum among women (Daftary et al., 1992). Carcinoma of the gingivae generally arises in the premolar and molar regions and more frequently, on the lower than on the upper arch (Cady and Catlin, 1969). These correspond to the sites of retention of tobacco quid in those who practice the habit.

\subsection{The palate}

Squamous cell carcinomas of the palate are in the Western countries and the United States (Daftary et al., (1992). Again, incidence significantly reflects different habits. In India, for example where the habit of "reverse smoking" is prevalent among the population, the relative frequency of squamous cell carcinoma of the palate is high (Gupta et al., 1980; Daftary et al., 1992). The habit of reverse smoking is exemplified by the practice of placing the glowing end of a local form of cigar called "chuttas" inside the mouth. In areas where reverse smoking is practiced palatal cancer comprise 38 to 48 percent of all oral cancers (Gupta et al., 1980; Daftary et al., (1992). Lesions of the hard palate may arise in the midline or to one side close to the palatal gingivae (Batsakis, 1979).

Primary squamous cell carcinomas arising in the soft palate are uncommon, accounting for 2 percent of overall oral cancer in reverse-smoking areas (Ramulu et al., 1973), but only 0.4 percent in non-reverse smoking areas (Wahi et al., 1965). However, reports of later studies by Mashberg and Meyers (1976) indicated a greater frequency of lesions primarily arising from the soft palate than is ordinarily documented with the "late" symptomatic lesions. On analyzing the site distribution of 222 cases of early asymptomatic OSCCs, the authors found that 64 of these (28.8 percent) occurred in the "soft palate complex" comprising the soft palate, anterior pillar of fauces, and retromolar trigone. Thus, some of the lesions designated hard palate lesions at the time of diagnosis may have earlier arisen from the soft palate before spreading to the hard palate at a late symptomatic stage.

\section{Diagnosis and management of oral cancer}

Early diagnosis of oral cancer has emerged as a priority public health objective whereby oral health professional play leading role (Neville and Day, 2002). It is presumed that early diagnosis of cancer should lead to less damage from interventional treatment and to a better 
prognosis. Because most individual are seen more commonly by primary care physicians and general dentists than by specialists, it is imperative for these clinicians to perform screening examinations to identify potential oral and pharyngeal cancers. In addition to the need for improved early detection by clinicians, it is also important that the patient and general public are knowledgeable about the disease (Yellowitz and Goodman, 1995; CDC, 1998). Delays in identification and recognition of suspicious lesions contribute to advanced stage at diagnosis and lower survival statistics (Shafer, 1975; Hollows, McAndrew and Perini, 2000).

\subsection{Diagnosis of oral cancer}

A distinction has been made in the early detection of oral cancers between "screening" (test aimed at evaluating presence of the disease in asymptomatic individuals) and "detection of cases" (applying specific procedure to patients with a suspicious lesion; Lestón and Dios, 2010). Nevertheless, conventional visual examination accompanied by palpation of suspicious lesions remains the gold standard screening methodology for oral precancer and cancer, while biopsy and histopathologic examination remains the universal diagnostic confirmatory test of choice (Lestón and Dios, 2010). Thus, in spite of the availability of several techniques that have been advocated as aids to oral cancer diagnosis (summarized in Table; adapted from Lestón and Dios, 2010) suspected malignant lesions must be biopsied in order to establish a definitive diagnosis.

\begin{tabular}{|l|}
\hline Toluidine blue \\
\hline Light-based detection systems \\
\hline Chemiluminescence (ViziLite Plus $® ;$; Microlux/DL $\circledR$ ) \\
\hline Tissue fluorescence imaging (VELscope $\left.{ }^{\circledR}\right)$ \\
\hline Tissue fluorescence spectroscopy \\
\hline Cytology or brush biopsy (OralCDx®) \\
\hline Specific analysis (, SCCAA, IAP, CYFRA, , and others) \\
\hline Specific analysis (, , CYFRA 21-1, TPS, IL-1B, DUSP 1, HA3, , , SAT, miRNA, and others) \\
\hline Imaging (DPT, CT, CBCT, MRI) \\
\hline
\end{tabular}

Table 1. Some techniques advocated for the clinical diagnosis of OSCC supplementing conventional oral examination, and histopathologic examination of suspicious lesions (adapted from Lestón and Dios, 2010).

In turn, the accurate diagnosis of potentially malignant and malignant oral lesions depends on the quality of the biopsy, selection of appropriate technique (e.g. incisional versus excisional), the applicability of the adequate clinical information, and competent interpretation of the biopsy results. Oral biopsy specimens can be affected by a number of artifacts resulting from crushing, fulguration, injection, or incorrect fixation and freezing (Trullenque-Eriksson et al., 2009). Results of cytologic examination of specimens obtained from non-invasive procedures such as brush biopsies or comparable techniques must not constitute the sole basis for a diagnosis of malignancy (or the absence) leading to definitive treatments. This is because these non-invasive techniques often are fraught with several pitfalls accounting for high rates of false-negative and false-positive results. 


\subsection{Management of oral cancer patients}

While an exhaustive discussion on the management of oral cancer and precancerous lesions is not intended in this review, it is generally recommended that leukoplakias exhibiting degrees of epithelial dysplasia equal to, or worse than, moderate epithelial dysplasia be removed completely when possible (Epstein et al., 2007). On the other hand, the management guideline for mild dysplastic lesions is far less standardized with varied schools of thought ranging from those advocating a "wait-and-see" approach to those advocating total removal of all dysplastic lesions regardless of the degree of epithelial dysplasia. In addition, management decisions for mild epithelial dysplasia appear to be influenced by the size, location, and apparent etiologic factor accounting for the lesion. Some early dysplastic lesions where an etiologic agent (e.g. smoking) is identified have been known to regress and may reverse to normal on elimination of the etiologic factor responsible.

Patients with invasive oral cancer are best managed by a coordinated, multidisciplinary team of health care professionals, which may include a head and neck surgeon, oral and maxillofacial pathologist, general pathologist, radiation oncologist, neuroradiologist, reconstructive surgeon, medical oncologist, general dentist, oral and maxillofacial surgeon, maxillofacial prosthodontist, dental hygienist, nurse specialist, speech pathologist, nutritionist, and tobacco cessation counselor (Ord and Blanchaert, 2001).

Up to 15 percent of individuals with oral cancer harbor a second primary, making a complete head and neck examination that includes the larynx imperative (Lippman and Hong, 1989). Endoscopy of the larynx, esophagus, trachea, and lungs to rule out the possibility of other lesions in the high-risk patient is now performed routinely. For patients who present with a neck mass but no obvious primary site (or if the neck mass is more amenable to biopsy than the primary tumor), a fine needle aspiration remains the diagnostic method of choice rather than an open biopsy, because open biopsy has been reported to be related to a lower survival rate when not accompanied by a simultaneous neck dissection (Lefebvre et al., 1990; Kleid and Millar, 1993).

Also, imaging studies are now routines during the evaluation of primary oral tumors and neck disease. Both contrast-enhanced computed tomographic (CT) scans and magnetic resonance imaging (MRI) may be utilized in determining the extent of the primary tumor, invasion, regional node status, and distant metastasis, thereby providing important staging information (Som, Curtin and Mancuso, 1999, Robbins, 1999). Positron emission tomography (PET) scans are also becoming an increasingly popular tool for the identification of primary, recurrent, and metastatic diseases.

The treatment options for primary OSCCs are variable and depend on the size and location of the tumor, lymph node status, presence or absence of distant metastases, the patient's ability to tolerate treatment, and the patient's desires. Surgery and/or radiation therapy remain the gold standards for treatment of cancers of the lip and oral cavity. Oropharyngeal cancer may be treated with surgery and/or radiation therapy for early-stage disease. For advanced-stage disease, surgery with adjuvant radiation therapy may be indicated, although recent evidence suggests that the addition of chemotherapy to radiation therapy may provide a survival advantage over radiation therapy alone in this population (Forastiere, 1998; Calais et al., 1999). It is important to take into account disease status and 
prevalence of occult disease in the neck when evaluating primary cancers of the lip, oral cavity, and oropharynx (Robbins et al., 2001). Regardless of the treatment modality used, many patients will require consideration of problems related to airway protection, enteral feedings, xerostomia, mucositis, dysphagia, and voice change.

\section{References}

Ahlbom HE. Simple achlorhydric anaemia, Plummer-Vinson syndrome and carcinoma of the mouth, pharynx and oesophagus in women. Br Med J 1936; 2: 331-333.

Andre K, Schraub S, Mercier M, et al. Role of alcohol and tobacco in the aetiology of head and neck cancer: A case-control study in the Doubs region of France. Oral Oncol, Eur J Cancer 1995; 31B: 301-309.

Banoczy J, Csiba A. Occurrence of epithelial dysplasia in oral leukoplakia. Oral Surg 1976; 42:766-774

Barnard NA, Scully C, Eveson JW, et al. Oral cancer development in patients with oral lichen planus. J Oral Pathol Med 1993; 22: 421-424.

Barr BBB, Benton EC, McLaren K, Bunney MH et al. Human Papillomavirus infection and skin cancer in renal allograft recipients. Lancet 1989; I: 124-128.

Batsakis JG. Tumors of the Head and Neck, Clinical and pathologic Consideration,, 2nd Edition 1979. Ch. 6, pp144-146. Baltimore: Williams and Wilkins Co.

Bennie WH. A perspective of oral cancer: Epidemiology and aetiology of oral cancer in Britain. Proceedings of the Royal Society of Medicine 1976; 69: 737-740.

Bernia JL. Carcinoma of the lip: preliminary statistical analysis of eight hundred and twentyseven cases. J Am Dent Assoc 1948; 36: 262-270.

Blot WJ, McLaughlin JK,Winn DM, et al. Smoking and drinking in relation to oral and pharyngeal cancer. Cancer Res 1988; 48: 3282-3287.

Bouquot JE, Meckstroth RL. Oral cancer in a tobacco-chewing U.S. population - no apparent increased incidence or mortality. Oral Surg Oral Med Oral Pathol Oral Radiol Endod 1998; 86:697-706

Bradford CR, Hoffman HT, Wolf GT, Carey TE, Baker SR, McClatchey KD. Squamous carcinoma of the head and neck in organ transplant recipient: possible role of oncogenic viruses. Laryngoscope 1990; 100: 190-194.

Brown RL, Suh JM, Scarborough JE, et al. Snuff dippers' intraoral cancer: Clinical characteristics and response to therapy. Cancer 1965; 18: 2-13.

Brown RL, Suh JM, Scarborough JE, Wilkins SA Jr., Smith RR. Snuff dipper's intraoral cancer: clinical characteristics and response to therapy. Cancer 1965; 18: 2-13.

Cady B, Catlin D. Epidermoid carcinoma of the gum: A 20-year survey. Cancer 1969; 23: 551596.

Calais G, Alfonsi M, Bardet E, et al. Randomized trial of radiation therapy versus concomitant chemotherapy and radiation therapy for advanced-stage oropharynx carcinoma. J Natl Cancer Inst 1999; 91: 2081-2086.

Carpenter RD,Yellowitz JA, Goodman HS. Oral cancer mortality in Maryland. Maryland Med J 1993; 42: 1105-1109.

Centers for Disease Control and Prevention. Preventing and controlling oral and pharyngeal cancer. Recommendations from a national strategic planning conference. MMWR 1998; 47RR- 14. 
Chaturvedi AK, Engels EA, Anderson WF, Gillison ML. Incidence trends for human papillomavirus-related and -unrelated oral squamous cell carcinomas in the United States. J Clin Oncol 2008; 26: 612-9.

Clifford GM, Boyle P, Franceschi S. Human papilloma virus types in invasive cervical cancer worldwide: a meta-analysis. Br J Cancer 2003; 189: 12-19.

Cotran R, Kumar V, Robbins S. Environmental Pathology. In Robbins' Pathologic Basis of Diseases 1989; Ch. 9. Philadelphia: W.B. Saunders.

Daftary DK, Murti PR, Bhonsle RB, Gupta PC, Mehta FS, Pindborg JJ. Oral squamous cell carcinoma, In Oral Diseases in the Tropics, eds Patbhu SR, Wilson DS, Daftary DK, Johnson NW 1992. Ch. 37, pp. 429-448. Oxford: Oxford University Press.

Daftary DK, Murti PR, Bhonsle RB, Gupta PC, Mehta FS, Pindborg JJ. Risk factors and risk markers for oral cancer in high incidence areas of the world. In Oral Cancer: Detection of Patients and Lesions at High Risk, ed Johnson NW, 1991. Ch. 2. Cambridge: Cambridge University Press.

de Visscher JG, Bouwes Bavinck JN, van der Waal I. Squamous cell carcinoma of the lip in renal-transplant recipients. Report of six cases. Int J Oral Maxillofac Surg 1997; 26: 120-123.

Eisenberg E. Oral lichen planus: A benign lesion. J Oral Maxillofac Surg 2000; 58: 1278-1285.

Epstein JB, Sciubba J, Silverman S, Sroussi HY. Utility of toluidine blue in oral premalignant lesion and squamous cell carcinoma: continuing research and implications for clinical practice, Head Neck 2007; 29: 948-958.

Flaitz CM and Silverman S Jr. Human immunodeficiency virus (HIV)-Associated Malignancies. In Silverman S Jr (ed) Oral Cancer, 4th ed. Hamilton, Ontario, Canada: BC Decker, Inc., 1998: 165-170.

Flaitz CM, Nichols CM, Adler-Storthz K, et al. Intraoral squamous cell carcinoma in human immunodeficiency syndrome virus infection. A clinicopathologic study. Oral Surg Oral Med Oral Pathol Oral radiol Endod 1995; 80: 55-62.

Forastiere A, Goepfert H, Goffinet D, et al. NCCN practice guidelines for head and neck cancer. National Comprehensive Cancer Network Proceedings. Oncology 1998; 12: 39-247.

Gillison ML, Koch WM, Capone RB, Spafford M, Westra WH, Wu L, Zahurak ML, Daniel RW, Viglione M, Symer DE, Shah KV, Sidransky D. Evidence for a causal association between human papillomavirus and a subset of head and neck cancers. J Natl Cancer Inst 2000; 92: 709-20.

Goldenberg D, Harden S, Masayesva BG, Ha P, Benoit N, Westra WH, Koch WM, Sidransky $\mathrm{D}$, Califano JA. Intraoperative molecular margin analysis in head and neck cancer. Arch Otolaryngol Head Neck Surg 2004; 130: 39-44.

Gupta PC, Mehta FS, Daftary DK, et al., Incidence rates of oral cancer and natural history of oral precancerous lesions in a 10 -year follow-up study of Indian villagers. Commun Dent Oral Epidemiol 1980; 8: 287-333.

Harris C, Warnakulasuriya KAAS, Gelbier S, Johnson NW, Peters TJ. Oral and dental health in alcohol misusing patients. Alcohol Clin Exp Res 1997; 21: 1707-9.

Hollows P, McAndrew PG, Perini MG. Delays in the referral and treatment of oral squamous cell carcinoma. Br Dent J 2000; 188: 262-265.

Ibrahim K, Jafarey NA, Zuberi SJ. Plasma vitamin "A" and carotene levels in squamous cell carcinoma of the oral cavity and oro-pharynx. Clin Oncol 1977; 3: 203-207. 
Jemal A, Siegel R, Ward E et al. Cancer statistics, 2008. CA Cancer J Clin 2008; 58:71-96. Sargeran K, Murtomaa H, Safavi SM, Vehkalahti MM, Teronen O. Survival after diagnosis of cancer of the oral cavity. Br J Oral Maxillofac Surg. 2008; 46: 187-191.

Jemal A, Siegel R, Xu J, Ward E. Cancer statistics, 2010. CA Cancer J Clin 2010; 60:277-300.

Johnson NW. A global view of the epidemiology of cancer of oral cancer. In Oral Cancer: Detection of Patients and Lesions at Risk, ed. Johnson, N.W. 1991. Ch.1. Cambridge: Cambridge University Press.

Johnson NW. Tobacco use and oral Cancer: a global perspective. J Dent Educ 2001; 65: 328339.

Joseph BK. Oral cancer: prevention and detection. Med Princ Pract 2002; 11(Suppl 1): 32-35,

Jovanovic A, Schulten EA, Kostense PJ, et al. Tobacco and alcohol related to the anatomical site of oral squamous cell carcinoma. J Oral Pathol Med 1993; 22:459-462.

Kato I, Nomura AM. Alcohol in the aetiology of upper aero-digestive tract cancer. Eur J Cancer Oral Oncol 1994; 30B: 75-81.

Kelly AB. Spasm at the entrance of the esophagus. Proc R Soc Med 1919; 12 (Laryngol Sect): 235.

Kleid S, Millar HS. The case against open neck biopsy. Aust N Z J Surg 1993; 63: 678-681.

Lee JJ, Hong WK, Hittelman WN, Mao L, Lotan R, Shin DM, Benner SE, Xu XC, Lee JS, Papadimitrakopoulou VM, Geyer C, Perez C, Martin JW, El Naggar AK, Lippman SM. Predicting cancer development in oral leukoplakia: ten years of translational research. Clin Cancer Res 2000; 6: 1702-1710.

Lefebvre JL, Coche-Dequeant B, Van JT, et al. Cervical lymph nodes from an unknown primary tumor in 190 patients. Am J Surg 1990; 160: 443-446.

Lestón JS, Dios PD. Diagnostic clinical aids in oral cancer. Oral Oncol 2010; 46: 418-422.

Lewin F, Norell SE, Johansson H, et al. Smoking tobacco, oral snuff, and alcohol in the etiology of squamous cell carcinoma of the head and neck. A population-based case-referent study in Sweden. Cancer 1998; 82:1367-1375.

Lippman SM, Hong WK. Second primary tumors in head and neck squamous cell carcinoma: The overshadowing threat for patients with early-stage disease. Int J Radiat Oncol Biol Phys 1989; 17: 691-694.

Main JHP, Lacavaliar DR. Smokeless tobacco and oral disease: a review. J Can Dent Assoc 1988; 54: 586-591.

Mashberg A, Boffetta P,Winkelman R, et al. Tobacco smoking, alcohol drinking, and cancer of the oral cavity and oropharynx among U.S. veterans. Cancer 1993; 72:1369-1375.

Mashberg A, Samit A. Early diagnosis of asymptomatic oral and oropharyngeal squamous cancers. CA Cancer J Clin 1995; 45: 328-351

Mashberg A, Samit AM. Early detection, diagnosis, and management of oral oropharyngeal cancer. J Cancer Clinicians 1989; 39: 67-88.

Mashberg A. Diagnosis of early oral and oropharyngeal squamous carcinoma: obstacles and their amelioration. Oral Oncol. 2000; 36: 253-255.

McCarthy PL, Shklar G. Diseases of the Oral Mucosa, Diagnosis, Management, Therapy 1964. Ch. 29, pp. 304-328. New York: McGraw-Hill Book Company.

Murti PR, Bhonsle RB, Gupta PC, et al. Etiology of oral submucous fibrosis with special reference to the role of areca nut chewing. J Oral Pathol Med 1995; 24: 145-152.

Murti PR, Bhonsle RB, Pindborg JJ, et al. Malignant transformation rate in oral submucous fibrosis over a 17-year period. Community Dent Oral Epidemiol 1985; 13: 340-341. 
Neville BW, Damm DD, Allen CM, et al. Oral \& Maxillofacial Pathology. 2nd ed. Phila., PA: Saunders; 2009; 337-369.

Neville BW, Day TA. Oral cancers and precancerous lesions. CA cancer J Clin 2002; 52: 195215.

Ord RA, Blanchaert RH Jr. Current management of oral cancer. A multidisciplinary approach. J Am Dent Assoc 2001; 132: 19S-23S

Parkin SM, Laara E, Muir CS. Estimates of the worldwide frequency of sixteen major cancers in 1980. International Journal of Cancer 1988; 41: 184-197.

Paterson DR. A clinical type of dysphagia. Proc R Soc Med 1919; 12 (Laryngol Sect): 285-291.

Paymaster JC. Some observations on oral and pharyngeal carcinomas in the state of Bombay. Cancer 1962; 15: 578-583.

Prime SS, MacDonald DG, Rennie JS. The effects of iron deficiency on experimental oral carcinogenesis. Br J Cancer 1983; 47: 413-418.

Ramulu C, Raju MVS, Venkatarathnam G, Reddy CRRM. Nicotinic stomatitis and its relations to carcinoma of the hard palate in reverse smokers of chuttas. J Dent Res 1973; 52: 711-718.

Reddout N, Christensen T, Bunnell A et al. High risk HPV types 18 and 16 are potent modulators of oral squamous cell carcinoma phenotypes in vitro. Infectious Agents and Cancer 2007; doi: 101186/1750-9378-2-21.

Reddout N, Christensen T, Bunnell A et al. High risk HPV types 18 and 16 are potent modulators of oral squamous cell carcinoma phenotypes in vitro. Infectious Agents and Cancer 2007; doi: 101186/1750-9378-2-21.

Reibel J: Prognosis of oral pre-malignant lesions: significance of clinical, histopathological, and molecular biological characteristics. Crit Rev Oral Biol Med 2003; 14: 47-62.

Rennie JS, MacDonald DG, Dagg JH. Quantitative analysis of human buccal epithelium in iron deficiency anaemia. J Oral Pathol 1982; 11: 39-46.

Rennie JS, MacDonald DG. Quantitative histologic analysis of the epithelium of the ventral surface of the hamster tongue in experimental iron deficiency. Archives of oral Biology 1982; 27: 393-397.

Ringertz N (ed). Cancer incidence in Finland, Iceland, Norway and Sweden. A comparative study by the cancer registries. Acta Pathologica Microbiologica Scandinavia, Section A, Supplement 224, pp 105.

Robbins KT, Atkinson JL, Byers RM, et al. The use and misuse of neck dissection for head and neck cancer. J Am Coll Surg 2001; 193: 91-102.

Robbins KT. Integrating radiological criteria into the classification of cervical lymph node disease. Arch Otolaryngol Head Neck Surg 1999; 125: 385-387.

Rosenfield L, Callaway J. Snuff dipper's Cancer. Am J Surg 1963; 106: 840-844.

Sawyer DR, Wood NK. Oral cancer: Etiology, recognition and management. In The Dental Clinics of North America. Topics in Oral Dignosis I, eds. D'Ambrosia JA, Fotos PG. 1992; 36: 919-944.

Schantz SP,Yu GP. Head and neck cancer incidence trends in young Americans, 1973-1997, with a special analysis for tongue cancer. Arch Otolaryngol Head Neck Surg 2002; 128: 268-274.

Schwartz SR, Yueh B, McDougall JK, Daling JR, Schwartz SM. Human papillomavirus infection and survival in oral squamous cell cancer: a population based study. Otolaryngol Head Neck Surg 2001; 125: 1-9. 
Scully C. Oncogenes, tumor suppressors and viruses in oral squamous carcinoma. J Oral Pathol Med 1993; 22: 337-347.

Seoane J, Varela-Centelles P, Ramirez J.R, Romero MA, De La Cruz A. Artefacts produced by suture traction during incisional biopsy of oral lesions, Clin Otolaryngol 2002; 27: 549-553.

Shafer WG. Initial mismanagement and delay in diagnosis of oral cancer. J Am Dent Assoc 1975; 90: 1262-1264.

Silverman S Jr, Dillon WP, Fischbein NJ. Diagnosis In: Silverman S Jr ed. Oral Cancer. 4th ed. Hamilton, Ontario, Canada: BC Decker Inc; 1998; 41-66.

Silverman S Jr, Gorsky M, Lozada-Nur F, et al. A prospective study of findings and management in 214 patients with oral lichen planus. Oral Surg Oral Med Oral Pathol 1991;72:665-670.

Silverman S Jr, Griffith M. Smoking characteristics of patients with oral carcinoma and the risk for second oral primary carcinoma. J Am Dent Assoc 1972; 85:637-640.

Silverman S Jr, Shillitoe EF. Etiology and Predisposing Factors. In: Silverman S Jr ed. Oral Cancer, 4th ed. Hamilton, Ontario, Canada: BC Decker Inc; 1998, 7-24.

Silverman S Jr. Demographics and occurrence of oral and pharyngeal cancers. The outcomes, the trends, the challenge. J Am Dent Assoc 2001; 132: 7S-11S.

Singh AD, von Essen CF. Buccal cancer in South India. Etiologic and clinical aspects. Am J Roentgenol 1966; 96: 6-14.

Som PM, Curtin HD, Mancuso AA. An imaging-based classification for the cervical nodes designed as an adjunct to recent clinically based nodal classifications. Arch Otolaryngol Head Neck Surg 1999; 125: 388-396.

Spitzer WO, Hill GB, Chambers LW, Helliwell BE, Murphy HB. The occupation of fishing as a risk factor in cancer of the lip. New Engl J Med 1975; 293: 419-424.

Stich HF, Rosen MP, Hornby AP, Mathew B, Sankaranarayan R, Nair MK. Remission of oral leukoplakias and micronuclei in tobacco/betel quid chewers treated with $\mathrm{B}$ carotene plus vitamin A. Int J Cancer 1988; 42: 195-199.

Stich HF, Rosen MP, Hornby AP, Mathew B, Sankaranarayan R, Nair MK. Response of oral leukoplakias to the administration of vitamin A. cancer letters 1988; 40: 93-101.

Syrjanen S. Human papilloma virus (HPV) in head and neck cancer. J Clin Virol 2005; 32: (suppl) 59-66.

Syrjanen S. Human papilloma virus (HPV) in head and neck cancer. J Clin Virol 2005; 32: (suppl) 59-Kang MK, Park N-H. Conversion of normal to malignant phenotype: telomere shortening, telomerase activation, and genomic instability during immortalization of human oral keratinocytes. Crit Rev Oral Biol Med 2001; 12: 3854

Trullenque-Eriksson A, Muñoz-Corcuera M, Campo-Trapero J, Cano-Sanchez J, BasconesMartinez A. Analysis of new diagnostic methods in suspicious lesions of the oral mucosa, Med Oral Patol Oral Cir Bucal 2009; 14: E210-E216.

van Zuuren EJ, de Visscher JGAM, Bouwes Bavinck JN. Carcinoma of the lip in kidney transplant recipients. J Amer Acad Dermatol 1988; 38: 497-499.

Wahi PN, Lahiri B, Kehar U, Arora S. Oral and oropharyngeal cancers in North America. Br J Cancer 1965; 19: 627-641. 
Warnakulasuriya KA, Tavassoli M, Johnson NW. Relationship of p53 overexpression to $\beta$ other cell cycle regulatory proteins in oral squamous cell carcinoma. J Oral Pathol Med 1998; 27: 376-381.

Weinberger PM, Yu Z, Haffty BG, Kowalski D, Harigopal M, Brandsma J, Sasaki C, Joe J, Camp RL, Rimm DL, Psyrri A. Molecular classification identifies a subset of human papillomavirus--associated oropharyngeal cancers with favorable prognosis. J Clin Oncol 2006; 24: 736-47.

Winn DM, Blot WJ, Shy CM, et al. Snuff dipping and oral cancer among women in the southern United States. N Engl J Med 1981; 304:745-749.

Winn DM, Ziegler RG, Pickle LW, et al. Diet in the etiology of oral and pharyngeal cancer among women from the southern United States. Cancer Res 1984; 44: 1216-1222.

Winn DM. Diet and nutrition in the etiology of oral cancer. Am J Clin Nutr 1995;61:437S445S.

Wright Jm. Oral Precanerous lesions and conditions. Semin Dermatol 1994; 13:125-131

Wynder EL, Klein VE. The possible role of riboflavin deficiency in epithelial neoplasm. 1. Epithelial changes of mice in simple deficiency. Cancer 1965; 18: 167-180.

Wynder EL. The etiology aspects of squamous cell cancers of the head and neck. J Am Med Assoc 1971; 215: 452-453.

Yellowitz JA, Goodman HS. Assessing physicians' and dentists' oral cancer knowledge, opinions and practices. J Am Dent Assoc 1995; 126:53-59.

Zhang ZF, Morgenstern H, Spitz MR, et al. Marijuana use and increased risk of squamous cell carcinoma of the head and neck. Cancer Epidemiol Biomarkers Prev 1999; 8: 1071-1078. 


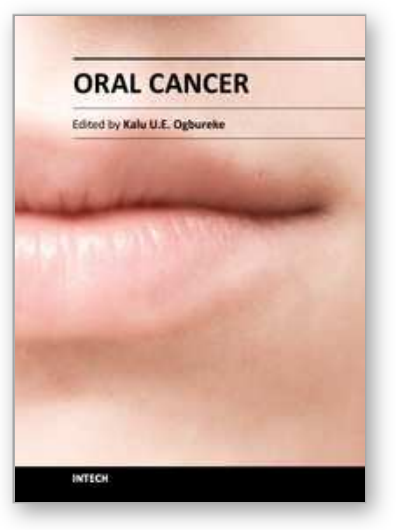

\author{
Oral Cancer \\ Edited by Dr. Kalu U. E. Ogbureke
}

ISBN 978-953-51-0228-1

Hard cover, 388 pages

Publisher InTech

Published online 14, March, 2012

Published in print edition March, 2012

Oral cancer is a significant public health challenge globally. Although the oral cavity is easily accessible, early diagnosis remains slow compared to the enhanced detection of cancers of the breast, colon, prostate, and melanoma. As a result, the mortality rate from oral cancer for the past four decades has remained high at over $50 \%$ in spite of advances in treatment modalities. This contrasts with considerable decrease in mortality rates for cancers of the breast, colon, prostate, and melanoma during the same period. This book attempts to provide a reference-friendly update on the etiologic/risk factors, current clinical diagnostic tools, management philosophies, molecular biomarkers, and progression indicators of oral cancer.

\title{
How to reference
}

In order to correctly reference this scholarly work, feel free to copy and paste the following:

Kalu U. E. Ogbureke and Christopher Bingham (2012). Overview of Oral Cancer, Oral Cancer, Dr. Kalu U. E. Ogbureke (Ed.), ISBN: 978-953-51-0228-1, InTech, Available from: http://www.intechopen.com/books/oralcancer/overview-of-oral-cancer

\section{INTECH}

open science | open minds

\section{InTech Europe}

University Campus STeP Ri

Slavka Krautzeka 83/A

51000 Rijeka, Croatia

Phone: +385 (51) 770447

Fax: +385 (51) 686166

www.intechopen.com

\section{InTech China}

Unit 405, Office Block, Hotel Equatorial Shanghai

No.65, Yan An Road (West), Shanghai, 200040, China

中国上海市延安西路65号上海国际贵都大饭店办公楼 405 单元

Phone: +86-21-62489820

Fax: +86-21-62489821 
(C) 2012 The Author(s). Licensee IntechOpen. This is an open access article distributed under the terms of the Creative Commons Attribution 3.0 License, which permits unrestricted use, distribution, and reproduction in any medium, provided the original work is properly cited. 